\section{Case Reports in Neurology}

\begin{tabular}{l|l}
\hline DOI: $10.1159 / 000475544$ & $\begin{array}{l}\text { C } 2017 \text { The Author(s) } \\
\text { Published by S. Karger AG, Basel } \\
\text { Published onlıne: IVIay I6, } 2017\end{array} \quad \begin{array}{l}\text { Karger } \\
\text { wwarger.com/crn }\end{array}$
\end{tabular}

This article is licensed under the Creative Commons Attribution-NonCommercial 4.0 International License (CC BY-NC) (http://www.karger.com/Services/OpenAccessLicense). Usage and distribution for commercial purposes requires written permission.

\title{
HIV-Associated Cerebellar Dysfunction and Improvement with Aminopyridine Therapy: A Case Report
}

\author{
Carolin Hoyer $^{\mathrm{a}} \quad$ Angelika Alonso $^{\mathrm{a}} \quad$ Beate Schlotter-Weigel $^{\mathrm{b}}$ \\ Michael Platten ${ }^{a}$ Marc Fatar $^{a}$ \\ ${ }^{a}$ Department of Neurology, University Medical Centre Mannheim, Mannheim, Germany; \\ ${ }^{b}$ Department of Neurology, Friedrich-Baur-Institute, Ludwig-Maximilians-University \\ Munich, Munich, Germany
}

\section{Keywords}

Cerebellar syndrome · HIV · 4-Aminopyridine

\begin{abstract}
Apart from infectious causes and cerebellar dysfunction associated with acquired immune deficiency syndrome dementia or HIV-associated neurocognitive disorder, cerebellar dysfunction in HIV-positive individuals has been ascribed to granule cell neuronopathy as well as primary cerebellar atrophy without identifiable etiology. We report the case of a patient with progressive cerebellar dysfunction as the primary manifestation of HIV infection. No symptom improvement was seen under combination antiretroviral therapy, which had been established upon diagnosis, but the patient improved rapidly under 4-aminopyridine treatment, which was recommended 1 year later. Our report, adding to the rather small number of reports of HIV-associated cerebellar atrophy and dysfunction as a primary manifestation of HIV infection, draws attention to HIV as a possible differential etiology of a cerebellar syndrome.
\end{abstract}




\section{Case Reports in Neurology}

Case Rep Neurol 2017;9:121-126

DOI: $10.1159 / 000475544$

\section{(c)}

2017 The Author(s). Published by S. Karger AG, Basel www.karger.com/crn

Hoyer et al.: HIV-Associated Cerebellar Dysfunction and Improvement with Aminopyridine Therapy: A Case Report

Further, rapid improvement of symptom severity under 4-aminopyridine treatment warrants further investigation with longer-term follow-up into the effectiveness of this compound in gait disorder associated with HIV infection.

(C) 2017 The Author(s)

Published by S. Karger AG, Basel

\section{Introduction}

Balance and gait disturbances and ataxia as manifestations of compromised cerebellar function frequently affect HIV-seropositive individuals. The spectrum of possible etiologies for cerebellar dysfunction in association with HIV infection is wide: ataxia is observed in conjunction with acquired immune deficiency syndrome (AIDS) dementia or HIV-associated neurocognitive disorder. Further, opportunistic infections such as toxoplasmosis, cerebellitis mainly caused by CMV and VZV infection as well as JC virus-related progressive multifocal leukoencephalopathy (PML) have been frequently identified as underlying causes, particularly prior to the establishment of combination antiretroviral therapy (cART). More recently, cerebellar dysfunction has also been ascribed to JC virus-associated granule cell neuronopathy (GCN) in the absence of PML [1]. Moreover, the possibility of an independent clinical entity of primary cerebellar atrophy in HIV-seropositive individuals after excluding other potential underlying causes has been discussed [2-5]. Here we report a case of an HIVpositive patient with cerebellar dysfunction and atrophy as the primary manifestation of HIV infection and, notably, rapid symptom improvement under treatment with 4-aminopyridine (4-AP).

\section{Case Presentation}

A 35-year-old man was referred to our hospital in June 2013 for diagnostic evaluation of a cerebellar syndrome, which had manifested in September 2011 with increasing difficulties in walking due to impaired balance. Tremor and dysarthria developed over the course of 2012, and increasing symptom severity eventually confined the patient to a wheelchair. During a hospital admission in January 2012 HIV infection was detected. Further relevant findings from that admission included a mild cerebellar atrophy in MRI and a cerebrospinal fluid pleocytosis of max. 98 cells/ $\mu \mathrm{L}$ with signs of lymphocytic activation as well as positive oligoclonal bands. HIV encephalopathy was diagnosed in 2012, and a cART with ritonavir (100 $\mathrm{mg}$ /day), darunavir (400 mg/day), and lamivudine/zidovudine (300/150 mg/day) was initiated. cART did not improve his neurological symptoms; rather, dysarthria worsened substantially over the next few months so that the patient could barely articulate intelligible words. Reduced mobility necessitated help with most daily life activities. Physical treatment was started in December 2012 and improved his ataxia somewhat so that he was able to walk short distances using crutches. Repeated clinical assessment in April 2013 resulted in a diagnosis of HIV-associated cerebellar syndrome, and oral treatment with 4-AP (25 mg/day) was recommended and started. Upon presentation in our hospital 3 months later, the patient displayed a cerebellar syndrome with broad-based ataxic gait, dysmetria, dysdiadochokinesis, slowed saccades, and dysarthria. He was able to walk freely for about $50 \mathrm{~m}$, balance was 


\section{Case Reports in Neurology}

Case Rep Neurol 2017;9:121-126

DOI: $10.1159 / 000475544$

(C)

C 2017 The Author(s). Published by S. Karger AG, Base ww.karger.com/crn

Hoyer et al:: HIV-Associated Cerebellar Dysfunction and Improvement with

Aminopyridine Therapy: A Case Report

impaired, leaving him unable to balance on one leg. His handwriting was slow but legible, according to his own report, it had significantly improved over the last few weeks. Scale for the Assessment and Rating of Ataxia (SARA) score [6] was 11.5. Muscle strength and sensory examination were normal. Spinal MRI was normal but brain MRI revealed marked cerebellar atrophy prominently affecting the midline structures in the absence of cerebellar lesions (Fig. 1). A mild atrophy of the cerebral cortex was also noted. Neurography and evoked motor and sensory potentials were normal, neuropsychologically, the patient displayed mild deficits in attention and executive function but no memory impairment. Blood HIV load was undetectable (below 20 copies/mL), CD4+ cell count (33.3\%; reference $44.4-72 \%$ of all lymphocytes) and CD4/CD8 ratio (0.5; reference 1-2.8) were reduced. Except for previous hepatitis B infection, blood testing turned out unremarkable including negative cryptococcal antigen, cytomegalovirus and toxoplasma early antibodies, paraneoplastic antineuronal antibodies (anti-Hu, -Yo, -Ri, -Ma1/2, -CV2, -Amphiphysin, -Tr), and negative JCV serum PCR. Cerebrospinal fluid analysis revealed normal cell count $(1 \mathrm{cell} / \mu \mathrm{L})$ but signs of intrathecal IG synthesis. Genetic testing for hereditary spinocerebellar ataxia (common types 1, 2, 3, 6, 7, 17) was negative (see also Table 1 for summary of differential diagnosis/etiology and diagnostic rule-out). The patient also denied prior and current excess consumption of alcohol and illicit drugs. Upon follow-up examination 3 months later, SARA score remained stable at 11.5 points so that continuation of the well-tolerated 4-AP therapy, cART as well as logopedic and physical therapy were recommended.

\section{Discussion}

We report a case of a cerebellar syndrome in an HIV-seropositive patient that is remarkable in two ways: first, it adds to the rather small number of reports of HIV-associated cerebellar atrophy and dysfunction as a primary manifestation of HIV infection, thus drawing attention to HIV as a possible differential etiology of a cerebellar syndrome. Second, rapid improvement of symptom severity under 4-AP treatment warrants further investigation with longer-term follow-up into the effectiveness of this compound in gait disorder associated with HIV infection.

An HIV-associated isolated cerebellar syndrome in the absence of identifiable infectious, toxic and (para)neoplastic agents, and partly as the initial manifestation of the infection, has been described by several authors [2-4, 7-10]. In some cases, JCV has been detected, and while earlier reports questioned the etiological significance of this finding [5], GCN was later proposed as a novel clinical entity underlying cerebellar granule cell destruction, sparing Purkinje cells and occurring either in isolation or in conjunction with PML lesions $[1,11]$. Definitive diagnosis of JCV GCN is established through cerebellar biopsy, displaying lytic infection of granule cells with JCV.

Since cerebellar biopsy and immunohistochemistry were not performed in all cases of otherwise unexplained cerebellar atrophy, one may, in retrospect, assume a proportion of those to be manifestations of cerebellar GCN. The etiology and pathomechanism of the remaining instances of cerebellar atrophy have not yet been elucidated, complicated by the fact that it is altogether a rare phenomenon in a heterogeneous patient population with 


\section{Case Reports in Neurology}

Case Rep Neurol 2017:9:121-126

DOI: $10.1159 / 000475544$

(C) 2017 The Author(s). Published by S. Karger AG, Basel www.karger.com/crn

Hoyer et al.: HIV-Associated Cerebellar Dysfunction and Improvement with Aminopyridine Therapy: A Case Report

varying degrees of immunosuppression. Hence, different mechanisms may be at work either alone or in conjunction.

The prevalent view regarding the neuropathology of HIV infection claims microglial or macrophage infection in the central nervous system with subsequent release of cytokines and chemokines to be a prominent mechanism of central nervous system damage and dysfunction [12]. Neurotoxic effects of HIV are attributable mainly to viral envelope proteins like gp41, gp120, and Tat. Gp41 was detected in the cerebellar dentate nucleus in HIVinfected individuals [13], and loss of neurons and neuronal density in the dentate nucleus and the inferior olivary nuclei was reported in HIV-positive patients [14]. Since the inferior olive delivers strong excitatory input to Purkinje cells, disruption of Purkinje cell signaling may follow. Vpr, another HIV accessory protein, can induce programmed cell death in the cerebellum [15], and the HIV coreceptor CXCR4 is highly relevant for cerebellar development, with continued expression into adulthood [16]. Additional suggestions for potential pathomechanisms of HIV-associated cerebellar dysfunction and degeneration have been put forward in the form of as yet unknown opportunistic infections and autoimmune mechanisms $[4,17]$; however, there is no evidence for loss of Purkinje cells in this regard. 4-AP has emerged as an efficient substance in the treatment of cerebellar ataxia and gait disorders [18]. With the pathomechanism(s) of cerebellar degeneration and dysfunction in HIV remaining elusive, the precise mode of action of 4-AP can only be speculated on. One may assume that, as has been repeatedly put forward that aminopyridines optimize the excitability of Purkinje cells [19]. However, since 4-AP failed to have any effect on the response of Purkinje cells to input from parallel fibers [20], an alternative theory proposes aminopyridines to normalize the rhythmicity of their firing [21, 22]. This offers therapeutic potential for a variety of pathologies associated with cerebellar dysfunction as Purkinje cells represent the sole output of the cerebellar cortex. In this regard, disrupted granule cell/Purkinje cell signaling as a pathomechanism underlying HIV-associated cerebellar dysfunction, which in turn may negatively impact Purkinje cell functioning, e.g., by de-rhythmizing their firing, could be targeted by 4-AP further downstream in the cerebellar circuitry.

Unfortunately, JCV PCR was not performed from cerebrospinal fluid in our case, so GCN can ultimately not be confirmed or ruled out, particularly since GCN may co-occur with PML but importantly may also manifest independently and may thus not necessarily be accompanied by one or more cerebellar lesions [23]. Yet, since no symptom improvement was observed upon the initiation of cART as would be more likely with GCN [11], one may argue against GCN as underlying cerebellar dysfunction in our patient. With regard to the lymphocytic pleocytosis initially observed, cerebellitis may be discussed as an alternative cause of the patient's symptoms, yet further laboratory testing and the absence of (contrastenhancing) lesions in repeated MRIs may argue against this possibility.

It would have been extremely useful to have a SARA rating before the initiation of 4-AP treatment, and longer-term follow-up examinations and ratings, in conditions of ongoing and paused 4-AP therapy, would be desirable to further evaluate the efficacy of 4-AP. However, since the patient had been undergoing physical therapy for quite some time when 4-AP treatment was initiated, it is unlikely that rapid improvement can be ascribed to physical therapy alone. In addition, no previous treatment had improved his dysarthria. 


\section{Conclusion}

Subacute or acute onset of a cerebellar syndrome should prompt workup including HIV diagnostics, and obtaining bioptic material from HIV-positive patients may aid the identification of underlying mechanisms. Aminopyridines may be considered in the treatment of gait disorder in the context of cerebellar atrophy.

\section{References}

1 Koralnik IJ, Wuthrich C, Dang X, et al: JC virus granule cell neuronopathy: a novel clinical syndrome distinct from progressive multifocal leukoencephalopathy. Ann Neurol 2005;4:576-580.

2 Agrawal RP, Jain A, Chahar C, et al: HIV presenting as cerebellar ataxia. J Assoc Physicians India 2015;6:75-77.

-3 Anand KS, Wadhwa A, Garg J: A case of cerebellar ataxia associated with HIV infection. J Int Assoc Provid AIDS Care 2014;5:409-410.

- Kwakwa HA, Ghobrial MW: Primary cerebellar degeneration and HIV. Arch Intern Med 2001;12:15551556.

5 Tagliati M, Simpson D, Morgello S, et al: Cerebellar degeneration associated with human immunodeficiency virus infection. Neurology 1998;1:244-251.

6 Schmitz-Hubsch T, du Montcel ST, Baliko L, et al: Scale for the assessment and rating of ataxia: development of a new clinical scale. Neurology 2006;11:1717-1720.

7 Elsheikh BH, Maher WE, Kissel JT: Cerebellar atrophy associated with human immunodeficiency virus infection. Arch Neurol 2010;5:634-635.

8 Graus F, Ribalta T, Abos J, et al: Subacute cerebellar syndrome as the first manifestation of AIDS dementia complex. Acta Neurol Scand 1990;2:118-120.

-9 Puertas I, Jimenez-Jimenez FJ, Gomez-Escalonilla C, et al: Progressive cerebellar syndrome as the first manifestation of HIV infection. Eur Neurol 2003;2:120-121.

-10 Yebra M, Garcia-Merino A, Albarran F, et al: Cerebellar disease without dementia and infection with the human immunodeficiency virus (HIV). Ann Intern Med 1988;2:310-311.

11 Tan CS, Koralnik IJ: Progressive multifocal leukoencephalopathy and other disorders caused by JC virus: clinical features and pathogenesis. Lancet Neurol 2010;4:425-437.

12 Kovalevich J, Langford D: Neuronal toxicity in HIV CNS disease. Future Virol 2012;7:687-698.

13 Weis S, Abe H, Mehraein P: Topography and frequency of the presence of HIV-antigens in brain tissue: a contribution to diagnostic tools. Clin Neuropathol 1993;12:277.

14 Abe H, Mehraein P, Weis S: Degeneration of the cerebellar dentate nucleus and the inferior olivary nuclei in HIV-1-infected brains: a morphometric analysis. Acta Neuropathol 1996;2:150-155.

15 Cheng X, Mukhtar M, Acheampong EA, et al: HIV-1 Vpr potently induces programmed cell death in the CNS in vivo. DNA Cell Biol 2007;2:116-131. Arnolds KL, Spencer JV: CXCR4: a virus's best friend? Infect Genet Evol 2014;25:146-156. Nagao S, Kondo T, Nakamura T, et al: A case of human immunodeficiency virus infection with cerebellar ataxia that suggested by an association with autoimmunity. Rinsho Shinkeigaku 2016;4:255-259.

18 Schniepp R, Wuehr M, Neuhaeusser M, et al: 4-aminopyridine and cerebellar gait: a retrospective case series. J Neurol 2012;11:2491-2493.

19 Kalla R, Glasauer S, Buttner U, et al: 4-aminopyridine restores vertical and horizontal neural integrator function in downbeat nystagmus. Brain 2007;130(Pt 9):2441-2451.

20 Alvina K, Khodakhah K: The therapeutic mode of action of 4-aminopyridine in cerebellar ataxia. J Neurosci 2010;21:7258-7268.

21 Stahl JS, Thumser ZC: 4-aminopyridine does not enhance flocculus function in tottering, a mouse model of vestibulocerebellar dysfunction and ataxia. PLoS One 2013;2:e57895.

-22 Strupp M, Kalla R, Claassen J, et al: A randomized trial of 4-aminopyridine in EA2 and related familial episodic ataxias. Neurology 2011;3:269-275.

-23 Wuthrich C, Cheng YM, Joseph JT, et al: Frequent infection of cerebellar granule cell neurons by polyomavirus JC in progressive multifocal leukoencephalopathy. J Neuropathol Exp Neurol 2009;1:1525 . 


\section{Case Reports in Neurology}

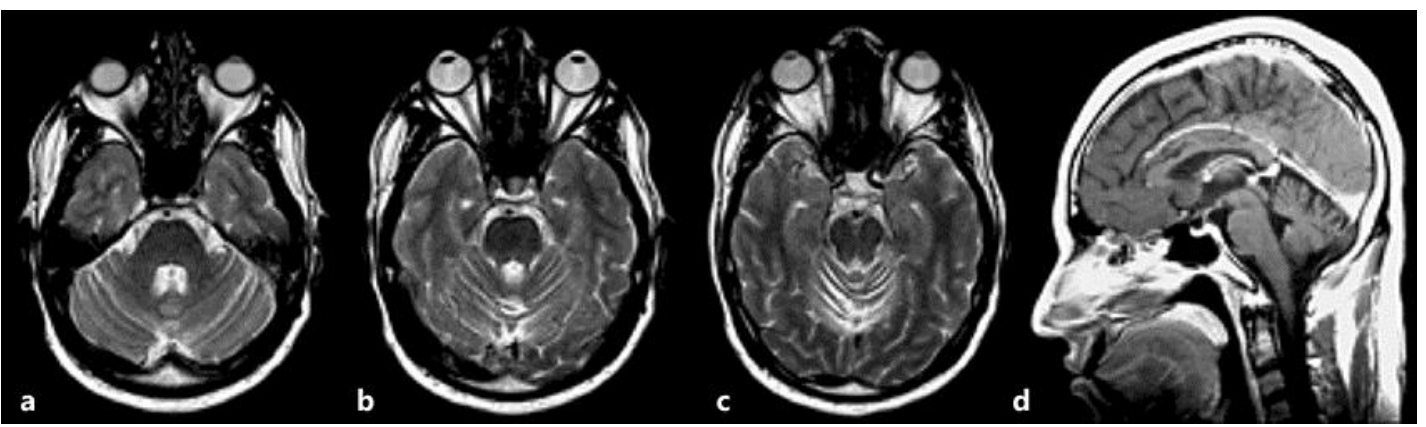

Fig. 1. T2-weighted axial (a-c) and post-contrast T1-weighted sagittal (d) MRI displaying marked cerebellar atrophy and, to a lesser degree, cortical atrophy without detection of contrast-enhancing lesions.

Table 1. Differential etiology of cerebellar syndrome and diagnostic rule-out

\begin{tabular}{ll}
\hline Etiology of cerebellar dysfunction & Ruled out by \\
\hline $\begin{array}{l}\text { Intake of toxic medication/ } \\
\text { substances }\end{array}$ & $\begin{array}{l}\text { medical history, bloodwork not suggestive of excessive alcohol } \\
\text { consumption }\end{array}$ \\
\hline Viral cerebellitis & $\begin{array}{l}\text { negative cerebrospinal fluid and bloodwork; no lesions or } \\
\text { contrast enhancement in MRI }\end{array}$ \\
\hline $\begin{array}{l}\text { Progressive multifocal leuko- } \\
\text { encephalopathy }\end{array}$ & $\begin{array}{l}\text { absence of (contrast-enhancing) lesions in MRI, negative JCV } \\
\text { serum PCR }\end{array}$ \\
\hline Paraneoplastic & $\begin{array}{l}\text { negative paraneoplastic antineuronal antibodies (anti-Hu, -Yo, } \\
\text {-Ri, -Ma 1/2, -CV2, Amphiphysin, -Tr) }\end{array}$ \\
\hline $\begin{array}{l}\text { Hereditary spinocerebellar ataxia } \\
\text { Cerebellar ataxia induced by } \\
\text { antiretroviral medication }\end{array}$ & genetic testing (most common forms) \\
\hline Granule cell neuronopathy & not definitely ruled out \\
\hline
\end{tabular}

